\title{
10. Is Indigenous poverty different from other poverty?
}

\author{
Boyd Hunter
}

\section{Closing the gaps and need for reflexivity on Indigenous disadvantage and poverty}

The Council of Australian Governments (COAG) adopted six targets in 2008 with the main aim to close the life expectancy gap within a generation. Specific goals are in the areas of mortality, access to early childhood education, reading, writing and numeracy achievements, Year 12 attainment and employment disadvantage. While none of the targets explicitly mention poverty, it would be unreasonable to ignore it and the associated financial stress as both are likely to condition the ability to achieve any of the targets identified. For example, standard measures of income poverty illustrates that many Indigenous people may lack the private resources required to facilitate the behaviour required to substantially improve health, attend educational institutions and even to look for and secure suitable work.

In order to reflect on Indigenous-specific nature of financial and resource needs, this chapter takes a further step back from income poverty that is usually defined using some societal norms of income adequacy. Given that Indigenous society in pre-colonial times was grounded in hunting and gathering activity, it would be appropriate to determine whether contemporaneous Indigenous economic activity includes a substantial non-market component that supplements income and otherwise substitutes for other financial needs.

Not only does this reflexivity allow an analysis of the adequacy of the standard poverty measures for Indigenous Australians, but it is consistent with the need to broaden the notions of poverty to take into account ongoing social relationships. Such considerations sometimes come under the rubric of social exclusion and this chapter briefly touches on such factors in order to provide a more complete reflection of some potential constraints on the ability to achieve various COAG targets that go beyond the lack of household resources. 
As the title of this chapter indicates, this research is motivated by the question:

- Is Indigenous poverty different from other poverty?

However, three other research questions are addressed in the research:

- Is there a role of customary Indigenous practices and non-market activities in explaining poverty and financial stress?

- Is income measurement error or household size and composition driving the difference between Indigenous and other Australian poverty?

- What is the relationship between poverty and social exclusion of Indigenous Australians?

The next section of this chapter discusses the existing debate about the difficulties of measuring poverty in the context of Indigenous Australians. After noting the main caveats on Indigenous poverty the incidence of poverty is described for selected household types with a particular focus on the those household categories where a disproportionate number of Indigenous people live. The third section introduces the theoretical and empirical issues for modelling financial stress, especially how social institutions, non-market activities and goods may interact with financial stress for Indigenous people. This discussion uses a paper by Breunig and Cobb-Clark (2006) to reflect on how poverty and equivalence scales might be fundamentally different for Indigenous people and other Australians. The next section discusses how social exclusion or social inclusion might yield additional insights into the nature of Indigenous disadvantage, inter alia, by teasing out how discrimination may weaken the association between income and poverty-related outcomes. The penultimate section provides clear answers to the research question identified above, while the conclusion discusses the implications of the analysis for future data collections.

\section{What is poverty and how might it relate to financial stress and social exclusion for Indigenous Australians?}

\section{What is poverty?}

Paul Spicker (2007) attempts to grapple with the idea of poverty and hence is a useful starting point for conceptualising what poverty might mean for Indigenous Australians. Spicker's book is even more ambitious than it sounds as it covers more than a narrow notion of deprivation of certain poor individuals as he outlines multiple definitions of underlying concept: 
- poverty in terms of being deprived of certain goods and services (i.e. as a specific need)

- poverty as a pattern of deprivation over an extended period of time

- poverty as a low standard of living with low income or consumption

- poverty as a lack of resources (which results in unmet need)

- poverty as an economic distance (or economic inequality where people cannot afford things that others can afford)

- poverty as economic class, which is determined itself by a person's relationship to the means of production

- poverty as social class, which is often defined in terms of low socioeconomic status where poor people lack status power and opportunities available to others

- poverty as a dependency on social assistance or welfare

- poverty as social exclusion where the poor are a marginal group who are excluded from society (either actively or passively). The poor may be unable to participate in society economically, socially or politically, or

- poverty as a lack of entitlement (e.g. Sen 1982).

Spicker classifies these definitions into three main clusters of poverty type categorised as: material need (i.e. the first 3 definitions above), economic circumstances (the next 3 definitions), and social relationships of people (the remaining 4 definitions).

Saunders, Naidoo and Griffiths (2007) conceptualised poverty, deprivation and social exclusion (the second last definition in Spicker's list) as three overlapping spheres that have a small central core that most people think of as social disadvantage. Historically, the concept of poverty has been operationalised in terms of a deficiency in income relative to some norm - however, there is some merit in considering a more expansive notion of social disadvantage. Notwithstanding, it is important to recognise there is a risk that we conflate analytically distinct phenomenon (i.e. the non-overlapping parts of Saunders, Naidoo and Griffiths' (2007) Venn diagram).

It is salutatory to remind ourselves that people mean different things when they refer to poverty, but the majority of this chapter will largely focus on the shortfall in income to meet the needs of Indigenous households - but the discussion will touch on some of the other meanings, notably some reflections on social exclusion in the penultimate section. 


\section{Difficulties in defining and measuring Indigenous poverty}

In order to contain the discussion to manageable size, the focus here is on several specific difficulties in defining and measuring Indigenous poverty - to highlight some factors that are sometimes go missing in broader poverty analysis (see Altman and Hunter 1998). Indigenous poverty differs from other Australian poverty in that is concentrated in large families where there are large numbers of children and complex demands on the household resources (compared to other Australian poverty where small sole-parent families and the elderly are overrepresented). The complexity of current living circumstances combines with historical Indigenous disadvantage to create both an inordinately high level of financial stress and a lack of capacity to deal with personal financial matters and the institutions that provide financial services. Any attempt to evaluate financial stress and develop this capacity to deal with financial institutions needs to take into account, and to some extent be informed by, specific social and cultural circumstances facing Indigenous Australians.

There are many conceptual complexities underlying Indigenous poverty that are not adequately captured in mainstream poverty analysis (Altman and Hunter 1997). A credible analysis must acknowledge both the diversity of Indigenous circumstances and how distinct value systems drive preferences and behaviours that shape the ability of policy to address Indigenous disadvantage. For example, the self determination movement led to many Indigenous people choosing to move to small remote communities (sometimes called outstations or homelands) that are distant from mainstream labour markets and commercial opportunities thus limiting the number of income earning possibilities and potentially putting the individuals concerned at risk of poverty. The more recent reaction to self-determination is critical of such moves, and the policies that support the decisions to move, as entrenching Indigenous poverty - however such criticisms tend to ignore the issue of Indigenous agency in the choices made.

Subsistence activities, sometimes referred to as 'home production' in the economics literature, also raise issues that complicate the interpretation of Indigenous poverty. Hunting, fishing and gathering play a central role in customary practices. Such activities not only provide direct sustenance which may substitute for goods purchased in the market place, these customary practices also play a crucial role in re-invigorating Indigenous culture and ultimately re-enforcing Indigenous identity - thereby enhancing the welfare of the Indigenous community in less material terms. Despite the intrusion of nonIndigenous settlement, hunting and gathering activities still play an important economic role in many remote and rural communities. Income-based measures used in conventional poverty analysis fail to capture the role of such informal 
productive, and income substitution activities. Some income-generating activities associated with customary activities may also not be captured if the money is generated in the 'gray' economy that operates outside formal reported income frameworks (especially the tax system).

Altman and Hunter (1997) analysis of the 1994 National and Torres Strait Islander Survey (NATSIS) data concluded that the substitution between nonmarket subsistence and monetary income was small as there is little difference between the personal income after accounting for hunting, fishing and gathering. Notwithstanding, it is important to revisit this issue in the context of financial stress as respondents may be less inclined to misrepresent their level of financial stress than misrepresent their level of income (survey respondents may (incorrectly) fear that income data may be compared to government tax records).

Daly and Smith (1995) suggests that Indigenous families experience substantial and multiple forms of economic burden arising from the size and structure of families and households. Indigenous households are more likely to have more than one family in residence than other Australian households and are more likely to be multi-generational with older Indigenous people more likely to be living with younger people in extended family households. Hunter, Kennedy and Smith (2003) and Hunter, Kennedy and Biddle (2004) demonstrate that the distinct structure of Indigenous households crucially determines the relative income position and ultimately, the incidence and severity of Indigenous poverty.

The issue of economies of scale in household production also has important implications for the measurement of Indigenous poverty. Equivalence scales used to control for the cost of various household types should accurately reflect the real cost of raising large complex Indigenous families with distinct sharing rules embedded in kinship networks and associated social obligations. Unfortunately, the range of conventional equivalence scales used by poverty researchers becomes significantly wider as the number of children increases (Whiteford 1985: 13, 106-7). This chapter is motivated partially by the need to demonstrate that Indigenous circumstances warrant a specific set of equivalence scales that take into account the distinct costs associated with running their households.

The role of relative prices and expenditure patterns may have a distinct effect on Indigenous people. When there are large differences in the relative price of daily necessities, it is difficult to compare the levels of poverty between groups (Sen 1992: 115). Given that Indigenous people are disproportionately concentrated in high-cost areas that are less accessible to mainstream services, the basic poverty comparisons between Indigenous and non-Indigenous Australians can be problematic. 
Ultimately, Indigenous poverty based on standard equivalence scales are misleading because the patterns of Indigenous expenditure on food, housing and transportation is likely to differ substantially from that of other poor people. Low-income Indigenous households appear to spend a higher proportion of their incomes on the basic necessities of life, than the lowest income households in the rest of Australian society. Indigenous expenditure patterns are also characterised by expenditure on poor quality, cheap foodstuffs, second-hand goods, reliance on credit and on subsidised services (Smith 1991). Obviously expenditure patterns like this partially reflect the high price of consumer goods and services in remote and rural areas, but this may also be indicative of cultural differences in the value of such goods.

In a sense, all these issues provide theoretical reasons why Indigenous poverty may be poorly measured. One consequence is that the processes driving financial stress will also be different for Indigenous and other Australians. A following section explores the distinct nature of financial stress among Indigenous people and the theoretical relationship between such stress and poverty. The empirical analysis of financial stress could be used as a rationale for revising equivalence scales to account for Indigenous circumstances and expenditure patterns. Before that, the following examines attempts to measure poverty using the modified Organisation for Economic Co-operation and Development (OECD) equivalence scales, which is the international standard used to control for the effects of household size and composition. It may turn out that these international standards are somewhat flawed in this situation, but they will form a useful benchmark to start our analysis of Indigenous poverty.

\section{Describing Indigenous poverty using OECD equivalence scales}

The incidence of poverty for various household types for Indigenous and all Australian households is reported in Fig. 10.1-10.3. The data for Indigenous Australians is drawn from the 2008 National Aboriginal and Torres Strait Islander Social Survey (NATSISS) and is broken down into estimates for remote and non-remote areas. As indicated above, we have good reason to expect that remote Indigenous populations are different to non-remote Indigenous population because accessibility to services in the latter is better by definition. It is also often argued that different colonial histories provide crucial context for understanding settled Australia and consequently remote and non-remote Indigenous peoples should be treated as distinct populations (e.g. Rowley 1970, 1972). Another reason for separating out the remote and non-remote populations is that very few non-Indigenous people live in remote areas - so most surveys of the Australian population concentrate solely on non-remote areas as the cost of surveying in remote areas is much higher. 
This analysis uses the 2006 General Social Survey (GSS) to benchmark the analysis for Indigenous Australians from the 2008 NATSISS, but the survey methodology of the GSS means that it is, strictly speaking, only comparable for the non-remote sample of NATSISS. The remote data from the NATSISS can be compared to the results for the non-remote NATSISS data to identify whether the experience of poverty in such areas is significantly different between Indigenous Australians living in remote and non-remote areas.

In this section, the poverty line is set as 50 per cent of the median equivalised income for the Australian households estimated using the 2006 GSS and inflated to 2008 levels, to make it comparable to the results for the 2008 NATSISS. This category of poverty line is not uncontested, but it is the most commonly used form benchmark to identify poor in Australia (Saunders 2005). The 95\% confidence intervals of the poverty measures, an indicator of reliability of estimates, are reported as 'whiskers' for respective columns. ${ }^{1}$

The incidence of poverty is not significantly different between various soleparents categories as shown in Fig. 10.1. About half of sole-parents live in households classified as poor irrespective of Indigenous status or the remoteness category. Being a sole-parent seems to put all Australians at a similar risk of being in poverty, as Indigenous estimates are not significantly different from the GSS estimate using 95\% confidence intervals. In contrast, Indigenous couples and other family types are significantly more likely to be in poverty than the analogous average Australian families in non-remote areas (with remote Indigenous couples experiencing even higher poverty rates).

The incidence of poverty is higher for Indigenous households than for other Australian households of all sizes as shown in Fig. 10.2. However, for the largest households (with 7 or more people in them) the difference is not significant largely due to the small number of non-Indigenous households of that size (and the consequent lack of reliability of associated estimates). The largest difference in the incidence of poverty for Indigenous and total Australian households is for households with 3-6 persons in them and the higher overall poverty rate for Indigenous people is driven by the disproportionate concentration of Indigenous households in larger households.

1 Confidence intervals are estimated using bootstrapped survey estimates of the standard errors of poverty. 
Survey Analysis for Indigenous Policy in Australia

Fig. 10.1 Poverty by family type, Australia, 2008

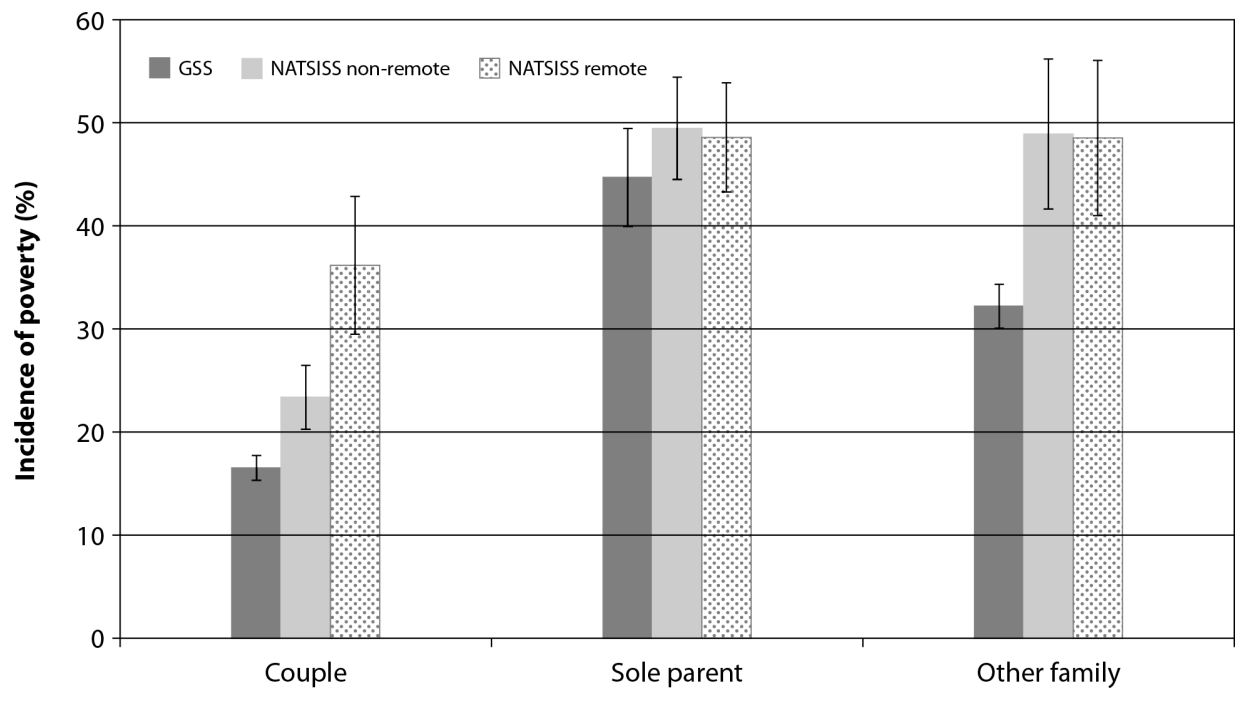

Family type

Source: Author's customised calculations using the 2008 NATSISS and 2006 GSS (accessed using the RADL)

Fig. 10.2 Poverty by household size, Australia, 2008

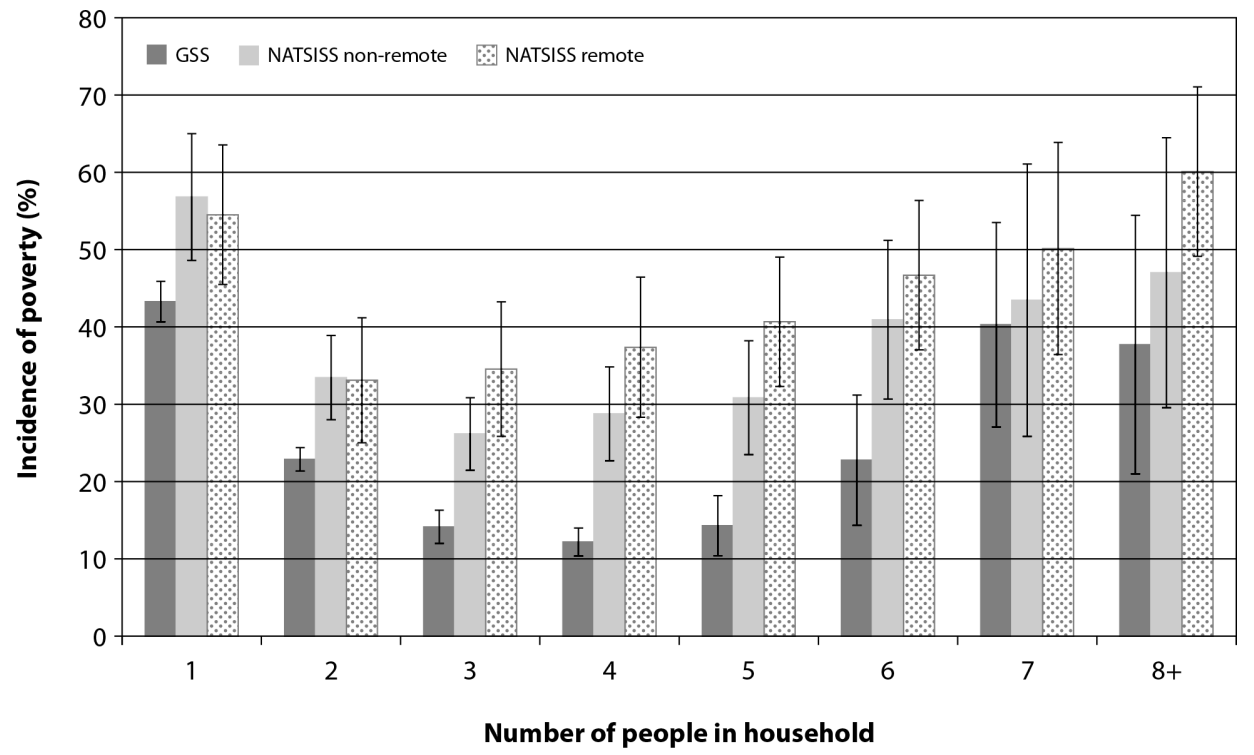

Source: Author's customised calculations using the 2008 NATSISS and 2006 GSS (accessed using the RADL) 
Fig. 10.3 Poverty by household type, Australia, 2008

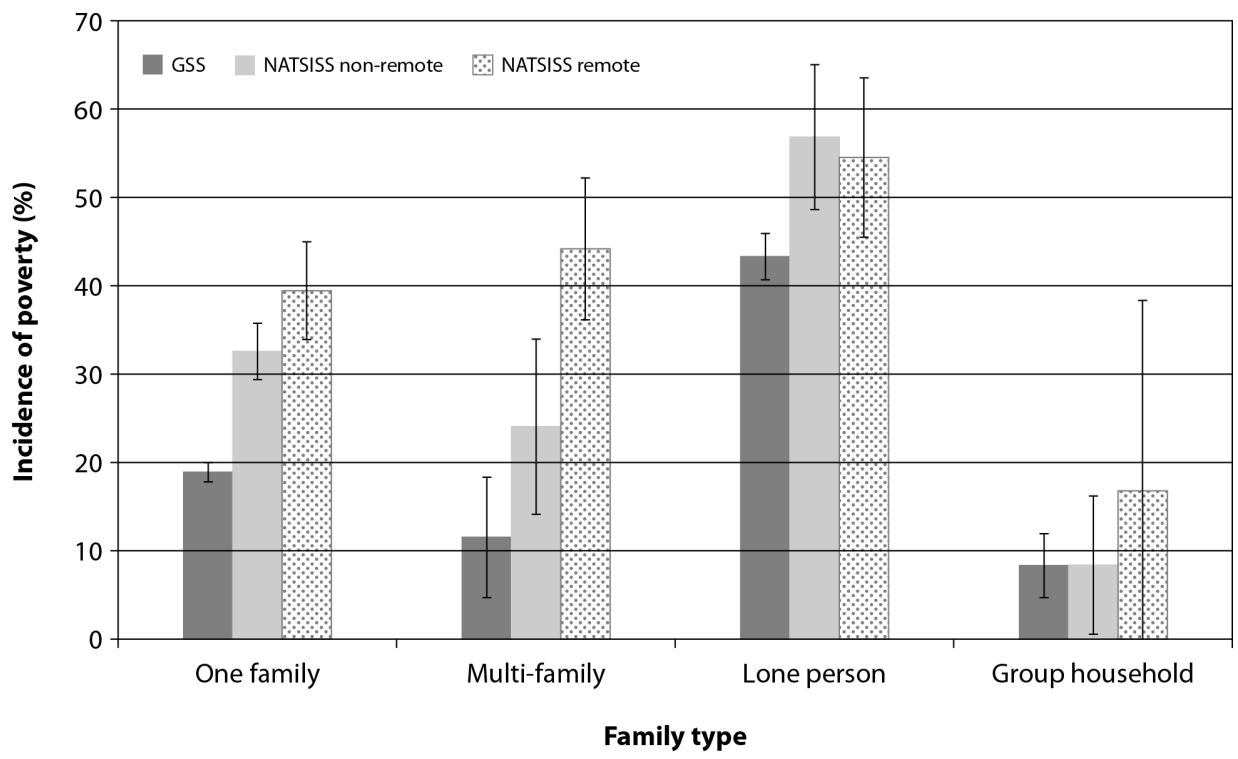

Source: Author's customised calculations using the 2008 NATSISS and 2006 GSS (accessed using the RADL)

The incidence of poverty is significantly higher in Indigenous population in most household types as documented in Fig. 10.3. Furthermore remote Indigenous households are very different to non-remote Indigenous households for both one family and multi-family household categories. Note that the poverty differentials are most pronounced in multi-family households where Indigenous population are between two and four times more likely to be classified as poor (for the non-remote and remote Indigenous populations respectively). As noted above, the incidence of multi-family households is about four times higher for Indigenous compared to other Australian households (see descriptive statistics for the following regression analysis of financial stress reported in Appendix 10A).

There has been some apparent improvement in Indigenous poverty rates since the mid 1970s, but the estimates are not directly comparable with those derived from the earlier NATSIS and related surveys (because of differences in data, methodology and measurement). The following discussion refers to broad trends and relativities to give a sense of the longer run trends in Indigenous poverty. Altman and Hunter (1998) report poverty rates for Indigenous and all Australians measured at the time of the Henderson Report and for the major family types Indigenous people were 2.5-3 times more likely to be in poverty than all Australians. Altman and Hunter (1998) also report estimates by Ross and Mikalauskas (1996) based on 1991 Census data showing that, in broad terms, Indigenous poverty was about 1.3 times that of non-Indigenous poverty 
for sole-parent families with children and 2.5 times that for non-Indigenous coupled families with children. The long run trends in reducing Indigenous poverty are positive since the 1970s, but it is less clear that they are significantly positive since 1991 as NATSISS based estimates reported above are broadly consistent with those in Ross and Mikalauskas (1996). The new estimates of poverty by remoteness status are one contribution of this chapter and it should be noted that the higher end of the range of measured relative poverty rates is usually associated with living in remote areas. The household types at most variance with the nuclear family archetype common in Western societies, such as multi-family households, are also one of the largest contributors to the apparent poverty rates for Indigenous people. One important research question is whether these observations reflect the circumstances of such families or are simply the product of measurement error caused by the imposition of assumptions that are inappropriate for many Indigenous households. The next section attempts to shed some light on this issue by analysing how the determinants of financial stress vary for Indigenous and other Australians. Given that poverty is an important factor underlying financial stress this allows us to indirectly get an insight into how the processes underlying poverty measurement may differ for groups of Australians.

\section{Financial stress and poverty}

\section{Modelling financial stress}

In general, financial stress represents the strain in a household associated with either a lack of financial resources or an inability to manage the resources available. After a brief reflection, it should be obvious that financial stress can be associated with people who are not income deficient or materially deprived. Financial stress can be associated with an inability to manage a debt burden effectively or even the lack of access to appropriate financial infrastructure. It must be acknowledged that there is no necessary identity between financial stress and poverty, but there is some scope for overlap. In modelling financial stress, it is important to attempt to control for factors that are associated with debt burden and access to financial infrastructure, so that some inference can be made about the factors that are more likely to be associated with poverty per se.

One background factor likely to be associated with financial stress is the financial skills and capability of individuals concerned. The Nobel Prize winner Amartya Sen has written conceptual contributions on poverty (e.g. the entitlement approach associated with his earlier work on famines) and capability (Sen 2000; see also Robeyns 2000: 5). 
Financial stress is one adverse outcome from a prolonged experience of poverty. Before financial hardship manifests itself, the lack of entitlements (or resources) relative to financial and consumption needs must be evident along with behaviours and institutional processes that either reinforce (or fail to address) the underlying deficit in resources, or do not facilitate a suitable line of credit. Like all poverty-related research, it is impossible to get away from the normative nature of the concept. It should be recognised that financial stress can arise from factors other than poverty - for example short-term unsustainable discretionary consumption and temporary circumstances and impediments to access to credit (i.e. where wealth and assets tied up for a short period). The lack of resources not only encompasses a lack of income, but may also include the lack of capacity to manage finances through either poor basic literacy and numeracy (or some more sophisticated notion of financial literacy) or the existence of networks of support and advice.

Identity economics expands upon the idea of preferences and behaviours being, at least in part, socially determined. In particular consumption preferences and other behaviours are shaped to group norms or identities. Such choices, that can easily be characterised as having a cultural dimension, may have positive or negative impacts on outcomes (Akerlof and Kranton 2010). Norms of behaviour and consumption are conditioned by identity and social relations, especially the extent to which an individual associated in social networks with 'like' people who have similar identification and characteristics.

In standard neo-classical economic models, household economic behaviour is based upon a model of households making consumption decisions within a household budget constraint so as to maximise their utility. In such a model, financial stress occurs as a result of an inadequate household budget (i.e. income poverty) or where a household considers that the 'household stress' has a lower disutility than the utility they gain from an alternative pattern of behaviour and consumption. Some outcomes may look like 'hardship', but are really a rational decision by an individual who weighs up anticipated utility and disutility of various consumption options. When examining financial stress of a subpopulation like Indigenous population, the fact that some consumption choices may be linked to social or cultural norms should be considered.

Sen (1993) describes a capability framework that provides a critique of the utilitarian approach adopted by neo-classical economists. Central to Sen's approach is that wellbeing should not be simply measured in terms of the actual outcomes that individuals achieve, but is intrinsically linked to the actual range of choices they have, and the extent to which these choices are constrained. 'Capability' refers to all the things people could do with the available resources to which they are entitled. 'Functioning' is another core concept in Sen's lexicon, which refers to what people actually decide to do with the resources that are 
available to them. 'Choice', or what sociologists refer to as individual agency, is a core feature in Sen's model. Of course, the rhetoric of choice is also essential to many conventional economic debates, but this is largely confined to people choosing what they want to buy or consume. Sen's model allows expansion of the notion of choice so that the capability set of individuals is extended - and so people's freedom to choose and develop is enhanced. ${ }^{2}$

Sen's (1993) model refers to entitlements that might include human capital (e.g. numeracy and literacy), income, non-market goods (hunting, gathering and home production) and social infrastructure. One might also argue that social capital or cultural capital is one form of resource as the experience of social networks may change the choices people make (Bourdieu 1993; Coleman 1988).

Understanding how Indigenous households engage in production, consumption, and savings behaviour is critical to postulating models for capturing aspects of financial stress, along with the failure to achieve wellbeing that is often characterised as poverty.

Breunig and Cobb-Clark (2006) outline a model of financial stress that allows them to make some inferences about how poverty is measured using equivalence scales. Their approach is to parsimoniously model the factors that drive financial stress, and then calculate the level of income that equates the financial stress (or rather underlying welfare) of households of various sizes and compositions after controlling for other relevant factors. Equivalence scales can be thought of as the income for a particular household type that equates the income required to achieve the same welfare in a reference household (say 2 adults and no children). The importance of such an analysis is that it might allow researchers to estimate an Indigenous-specific equivalence scales which could be compared to equivalence scales constructed for the total Australian or other populations using similar methodologies. While there is a theoretical link to the conventional equivalence scales, such as the OECD scale used above, the conventional scales are based on more complete information on consumption and expenditure patterns and a different analytic framework - accordingly, it would be preferable to make any conclusions about Indigenous-specific finding based on an empirical analysis that used the same methodology and as comparable data as is possible. Future research can and should fully operationalise the Breunig and CobbClark methodology, but that is beyond the scope of this chapter. The following research estimates the relationship of equivalised household income (rather than

\footnotetext{
2 Note that choice plays a vital role in Sen's (1993) model and is not taken as given as it is in most economic models (where choice finishes with purchase of the goods and services, or 'resources' might be used to achieve capability and functioning). In a sense, social inclusion is all about enlarging both the capability set and the choices made. The problem for a social inclusion agenda potentially occurs when value judgements are made about people's choices. It is an intrinsically political process of who is judging whom or what (Hunter 2009; Jordan and Hunter 2009).
} 
raw household income used in Breunig and Cobb-Clark) and salient household characteristics to financial stress, and hence it effectively takes existing equivalised scales as given. Notwithstanding, the following empirical strategy is largely symmetrical with that study, and it could be argued that difference between results for Indigenous and all Australians could be associated with differences in the appropriate equivalence scales for the respective populations.

Two specifications of financial stress are considered: a parsimonious specification that allows comparisons between Indigenous and overall Australian estimates and a non-parsimonious specification that controls for a range of factors that are likely to be particularly important in the Indigenous context. While the latter may provide a better description of the data, this non-parsimonious approach will enhance the possibility that reverse causation is affecting any estimated equivalence scales. Notwithstanding, several expanded specifications are used here in an attempt to tease out how the processes underlying poverty in Indigenous and other populations might differ substantially.

In addition to measuring the association between financial stress and income and household size and composition, some measure of Indigenous customary activities (such as living on homelands and hunting and gathering activities) and wealth as proxied by whether the dwelling is owned or being purchased (i.e. there is some equity in the household). Note that household composition also includes information on whether the household has more than one family living in it - however the effect of living in such households may be either positive or negative depending on how integrated are the resident families' finances and living conditions. Households that include both Indigenous and non-Indigenous members are also controlled for, as this will by definition affect the indigeneity of the household. In order to compare for between Indigenous and non-Indigenous populations, who tend to live in very different parts of the country, a highly disaggregated set of geographic indicators were used in the regression (Appendix 10A). Even though we have taken great care in constructing data that is basically comparable between the NATSISS and GSS for most variables, the geography is coded very differently. There is a real analytical problem that will be discussed further in the concluding section.

One approach may be to estimate separate regressions for remote and nonremote areas for NATSISS and control for other geography but this will make the estimate even less reliable than those estimated for the whole population. The following uses the whole sample, and controls for the unobserved geographic factors as best as possible using relatively disaggregated areal controls, to simplify exposition. 


\section{Selected data issues}

This section attempts to identify the factors associated with financial security/ stress for insight into the nature of Indigenous poverty relative to other Australian poverty.

The NATSISS includes several measures of either financial security or financial stress. Those who felt they were more financially secure are captured by whether or not they felt their household could raise \$2000 in an emergency. Financial stress over the previous 12 months is captured by whether or not they have run out of money for basic living expenses. There were other measures of financial security and financial stress on both the NATSISS and GSS files, but these were the only two variables where it is reasonably certain the variables were comparable between surveys. Even here there was an issue with the use of a dollar value in the financial security measure as the two surveys were conducted almost two years apart. However, the rate of inflation in Australia between the two surveys was only 4.3 per cent, so $\$ 2000$ at the time of the 2006 GSS was worth around $\$ 2086$ by the time the 2008 NATSISS was conducted. That is, it would have been slightly easier for a NATSISS respondent to raise the cash, but the difference was not substantial.

Financial stress is measured at the household level and therefore things that explain it should also be measured at that level. While it would be sensible to assume that a person's household context influences their individual outcomes, the reverse is not necessarily, or even likely to be, the case. Therefore in order to analyse household-level dependent variables using individual data, we should ideally have information on all members of the household so that the characteristics of the household can be fully described. The 2008 NATSISS survey method means that there is, at most, information from two adults in the household. That is, it is not possible to use this information to construct full household level data where there is only individual-level information available on the Remote Access Data Laboratory (RADL) - the method that allows researchers limited and controlled access to ABS confidentialised data). The good news is that the two adult individuals are randomly selected within the household so using individual information should provide an unbiased characterisation of the household - although this characterisation would necessarily be less reliable than if all the individuals in the household were used to estimate the average characteristic for the household.

For the GSS, information on only one respondent per household is provided so the person-level file on the unit record gives a unique correspondence with household level data (although not necessarily entirely accurate information on that level). That is, there is no choice about the individual identified with the household characteristics. The question then becomes: is the individual-level 
data used to characterise the household likely to have similar information on the GSS and NATSISS? Rather than use all individual-level data on the NATSISS file to construct some sort of household average, it is probably better to use one individual to characterise the household. The person chosen to represent the NATSISS household is the first person listed on the household file - whoever that might be. This has a direct analogy with the GSS respondent who, at the risk of being trite, is in effect the number one respondent.

Despite the logical deficiencies in using individual information to explain household-level phenomenon, I estimate some models with a household-level dependent variable (financial stress) using a mix of household and individual explanatory variables. However, this approach can be justified on the grounds that when separate models are estimated using household-level-only explanatory variables (Models 1 and 2, which are not reported to save space), the coefficients do not vary substantially from those reported (Models 3 and 4 ). ${ }^{3}$ Consequently, despite the flawed logic in the expanded specification that could confound the level of analysis and the effects of various explanatory factors, the coefficients for the household-level-only specifications appear to be robust.

One last data issue is that the financial stress measure is retrospective (over the last 12 months). Arguably, it is methodologically problematic to explain retrospective measures using current characteristics. Ideally one would want to analyse them using information on the household at the start of the period. This is only ever likely to be achieved using longitudinal data sets. Financial security is measured in terms of whether it is possible to raise cash within a week so the use of current values of explanatory variables does not pose any analogous methodological issue for that dependent variable.

\section{Factors associated with financial stress}

A logistic regression analysis similar to that done in Breunig and Cobb-Clark (2006) is provided in Tables 10.1 and 10.2. The specification excludes a few explanatory factors that we have theoretical reasons to be related to financial stress and security are omitted from the specification. Biddle (2011) provides a descriptive analysis that includes education and work. One reason to exclude these potential explanatory factors is that one of the aims of this exercise is to gain some indirect insight into equivalence scales which relate household

\footnotetext{
3 Model 1 only includes income and household size, Model 2 includes other household-level information that is coded by the ABS and we can be confident accurately characterises household-level data. Model 3 includes household-level variables derived from the first respondent on the unit record file, while Model 4 includes the broadest specification that also includes some Indigenous specific variables that attempt to capture the role of customary activities. Obviously, Model 4 can only be estimated using NATSISS data.
} 
income (measured in logs) and family composition to financial stress. Inclusion of education and market work will indirectly pick up the influence of market income on financial stress thereby changing the underlying coefficient on equivalised income which is crucial to the derived or implied estimates of equivalence scales.

Overall, the explanatory variables included in the model explain much less of the variation in financial stress than they did for financial security as evidenced by the lower Pseudo R-Squared and the fewer number of variables that were statistically significant. This is probably due in no small measure to the fact that financial stress is a retrospective measure, whereas this measure of financial security is prospective. It is more plausible to predict possible outcomes from the near future in terms of current circumstances rather than retrospectively explaining historical experience of financial stress in terms current information. Analysis which attempts to explain the past in terms of the present could be construed as rationalising the situation ex post, and hence can more easily be discounted as resulting in invalid conclusions.

The explanatory variables are the same in Tables 10.1 and 10.2 and given that financial stress is arguably the obverse of financial security, in general it is expected the coefficient for one to be the negative sign of the coefficient in the other regression. This is indeed the case for most coefficients reports in Tables 10.1 and 10.2. For example, the log of household income reduces financial stress and increases financial security. Not surprisingly, they are the coefficients in the respective regressions with the highest significance statistics.

Leaving aside the coefficients for the multi-family household variable for a moment, the second set of variables relate to wealth as embodied in the ownership of a large asset, most likely a house either with or without a mortgage. There is clear evidence that having a large asset improves the respondent's access to the credit market, probably through 're-draw', an increasingly common facility.

A geographic index that captures the local socioeconomic status of an area (Socio-Economic Indexes for Areas (SEIFA), an ABS measure using the Index of Relative Socio-Economic Disadvantage) is included along with the most disaggregated information available on the respective surveys. The lack of direct comparability of much of this geographic information in the GSS and NATSISS, along with the lack of analytical utility of some of that geographic information, is potential problematic for users of both surveys. This point will be discussed in greater detail later in this chapter.

The SEIFA data is coded into deciles which also provide a reasonably refined control for otherwise unobservable geographic factors. Given that it is known to be highly correlated with local amenity, and hence household prices, it will 
also pick up additional value of local assets, particularly housing prices. Living in higher status areas is associated with a considerably enhanced ability to raise cash quickly, which is consistent with the factor being associated with higher housing prices in such areas. In terms of financial stress, the SEIFA variable is associated with less cash problems for the GSS analysis but was not significantly associated with cash problems in the NATSISS sample. That may be a reflection of it being less important for the Indigenous population because relatively few Indigenous people live in high status areas and even fewer own houses in such areas.

Table 10.1 Factors associated with cash problems in the last 12 months, Australia, 2008

\begin{tabular}{|c|c|c|c|}
\hline & $\begin{array}{c}\text { GSS } \\
\text { Model } 3\end{array}$ & $\begin{array}{l}\text { NATSISS } \\
\text { Model } 3\end{array}$ & $\begin{array}{l}\text { NATSISS } \\
\text { Model } 4\end{array}$ \\
\hline Log of equivalised household income (OECD) & $\begin{array}{l}-0.4824 \\
(-12.12)\end{array}$ & $\begin{array}{r}-0.1996 \\
(-3.50)\end{array}$ & $\begin{array}{r}-0.2069 \\
(-3.62)\end{array}$ \\
\hline Number of people in household & $\begin{array}{r}0.1666 \\
(7.05)\end{array}$ & $\begin{array}{r}0.0985 \\
(4.24)\end{array}$ & $\begin{array}{r}0.0975 \\
(4.17)\end{array}$ \\
\hline Multi-family household & $\begin{array}{r}-0.0247 \\
(-0.13)\end{array}$ & $\begin{array}{r}-0.3579 \\
(-2.42)\end{array}$ & $\begin{array}{r}-0.3562 \\
(-2.40)\end{array}$ \\
\hline Owner without a mortgage & $\begin{array}{l}-2.0930 \\
(-25.19)\end{array}$ & $\begin{array}{r}-1.3290 \\
(-7.81)\end{array}$ & $\begin{array}{r}-1.3267 \\
(-7.76)\end{array}$ \\
\hline Owner with a mortgage & $\begin{array}{l}-0.6587 \\
(-10.65)\end{array}$ & $\begin{array}{r}-0.5309 \\
(-5.33)\end{array}$ & $\begin{array}{r}-0.5315 \\
(-5.27)\end{array}$ \\
\hline $\begin{array}{l}\text { Index of Relative Socio-Economic Disadvantage } \\
\text { (SEIFA index) }\end{array}$ & $\begin{array}{r}-0.0649 \\
(-6.17)\end{array}$ & $\begin{array}{r}0.0193 \\
(1.22)\end{array}$ & $\begin{array}{r}0.0178 \\
(1.12)\end{array}$ \\
\hline Couple family & $\begin{array}{r}-0.3113 \\
(-4.34)\end{array}$ & $\begin{array}{r}-0.2102 \\
(-1.83)\end{array}$ & $\begin{array}{r}-0.2089 \\
(-1.67)\end{array}$ \\
\hline One-parent family & $\begin{array}{r}0.6124 \\
(6.82)\end{array}$ & $\begin{array}{r}0.1934 \\
(1.76)\end{array}$ & $\begin{array}{r}0.1909 \\
(1.71)\end{array}$ \\
\hline Profound or severe disability & $\begin{array}{r}0.2851 \\
(2.55)\end{array}$ & $\begin{array}{r}0.5978 \\
(4.99)\end{array}$ & $\begin{array}{r}0.5965 \\
(4.95)\end{array}$ \\
\hline Unspecified disability & $\begin{array}{r}0.6463 \\
(9.31)\end{array}$ & $\begin{array}{r}0.3509 \\
(4.81)\end{array}$ & $\begin{array}{r}0.3528 \\
(4.78)\end{array}$ \\
\hline $\begin{array}{l}\text { Household includes Indigenous and non-Indigenous } \\
\text { residents }\end{array}$ & - & - & $\begin{array}{r}-0.0037 \\
(-0.04)\end{array}$ \\
\hline Live in homeland & - & - & $\begin{array}{r}-0.2113 \\
(-2.35)\end{array}$ \\
\hline Hunting \& gathering for medicines & - & - & $\begin{array}{r}0.2929 \\
(1.76)\end{array}$ \\
\hline Hunting \& gathering for food & - & - & $\begin{array}{r}0.0869 \\
(1.09)\end{array}$ \\
\hline Pseudo $\mathrm{R}^{2}$ & 0.1646 & 0.0765 & 0.0781 \\
\hline
\end{tabular}

a. T-statistics in brackets. The reference household for this analysis is an indigenous-only, lone person household (by definition a 'single family' household) in a dwelling that is not owned by occupants. The individuals in the reference category are those respondents who do not have a disability, live outside their 'homeland', and do not engage in hunting and gathering.

Source: Author's customised calculations using the 2008 NATSISS and 2006 GSS (accessed using the RADL) 
Table 10.2 Ability to raise $\$ 2000$ cash within a week, Australia, 2008

\begin{tabular}{|c|c|c|c|}
\hline & $\begin{array}{c}\text { GSS } \\
\text { Model } 3\end{array}$ & $\begin{array}{l}\text { NATSISS } \\
\text { Model } 3\end{array}$ & $\begin{array}{l}\text { NATSISS } \\
\text { Model } 4\end{array}$ \\
\hline Log of Equivalised household Income (OECD) & $\begin{array}{l}1.0079 \\
(21.45)\end{array}$ & $\begin{array}{l}1.0231 \\
(17.20)\end{array}$ & $\begin{array}{l}0.9973 \\
(16.70)\end{array}$ \\
\hline Number of people in household & $\begin{array}{r}-0.1395 \\
(-5.21)\end{array}$ & $\begin{array}{r}-0.0731 \\
(-3.30)\end{array}$ & $\begin{array}{r}-0.0658 \\
(-2.93)\end{array}$ \\
\hline Multi-family household & $\begin{array}{r}-0.0836 \\
(-0.41)\end{array}$ & $\begin{array}{r}-0.1553 \\
(-1.15)\end{array}$ & $\begin{array}{r}-0.1940 \\
(-1.42)\end{array}$ \\
\hline Owner without a mortgage & $\begin{array}{l}1.7340 \\
(21.63)\end{array}$ & $\begin{array}{l}1.8046 \\
(13.36)\end{array}$ & $\begin{array}{l}1.7300 \\
(12.70)\end{array}$ \\
\hline Owner with a mortgage & $\begin{array}{l}0.8953 \\
(12.18)\end{array}$ & $\begin{array}{l}1.1560 \\
(12.33)\end{array}$ & $\begin{array}{l}1.0664 \\
(11.25)\end{array}$ \\
\hline $\begin{array}{l}\text { Index of Relative Socio-Economic Disadvantage } \\
\text { (SEIFA index) }\end{array}$ & $\begin{array}{l}0.1355 \\
(11.55)\end{array}$ & $\begin{array}{r}0.0960 \\
(6.30)\end{array}$ & $\begin{array}{r}0.0883 \\
(5.72)\end{array}$ \\
\hline Couple family & $\begin{array}{r}0.3911 \\
(4.88)\end{array}$ & $\begin{array}{r}0.4560 \\
(4.37)\end{array}$ & $\begin{array}{r}0.1901 \\
(1.68)\end{array}$ \\
\hline One-parent family & $\begin{array}{r}-0.4828 \\
(-5.00)\end{array}$ & $\begin{array}{r}0.0166 \\
(0.16)\end{array}$ & $\begin{array}{r}-0.0887 \\
(-0.84)\end{array}$ \\
\hline Profound or severe disability & $\begin{array}{r}-0.3310 \\
(-2.94)\end{array}$ & $\begin{array}{r}-0.7440 \\
(-6.00)\end{array}$ & $\begin{array}{r}-0.7299 \\
(-5.84)\end{array}$ \\
\hline Unspecified disability & $\begin{array}{r}-0.6561 \\
(-8.88)\end{array}$ & $\begin{array}{r}-0.2850 \\
(-4.17)\end{array}$ & $\begin{array}{r}-0.2453 \\
(-3.54)\end{array}$ \\
\hline $\begin{array}{l}\text { Household includes Indigenous and non-Indigenous } \\
\text { residents }\end{array}$ & - & - & $\begin{array}{r}-0.5238 \\
(6.40)\end{array}$ \\
\hline Live in homeland & - & - & $\begin{array}{r}-0.0840 \\
(-1.02)\end{array}$ \\
\hline Hunting \& gathering for medicines & - & - & $\begin{array}{r}0.3103 \\
(1.94)\end{array}$ \\
\hline Hunting \& gathering for food & - & - & $\begin{array}{r}0.1352 \\
(1.80) \\
\end{array}$ \\
\hline Pseudo $\mathrm{R}^{2}$ & 0.2382 & 0.2225 & 0.2289 \\
\hline
\end{tabular}

a. T-statistics in brackets. The reference household for this analysis is an indigenous-only, lone person household (by definition a 'single family' household) in a dwelling that is not owned by occupants. The individuals in the reference category are those respondents who do not have a disability, live outside their 'homeland', and do not engage in hunting and gathering.

Source: Author's customised calculations using the 2008 NATSISS and 2006 GSS (accessed using the RADL)

Couple families and one-parent families would on balance have an expectation of reverse signs for the coefficients (if they are significant at all). For the whole population, living in a couple is protective against financial stress whereas lone parents are generally associated with such stress. Relationships status, that is either being in a couple relationship or being a lone parent, does not generally have a significant association with financial stress or security for the Indigenous respondents in NATSISS. The only exception to this observation is that living in a couple is associated with financial security if Indigenous-specific factors 
associated with customary activities are NOT controlled for. This probably indicates that Indigenous financial stress is complicated by the presence of such activities which directly augment household production.

Severe and profound disability and other disability are likely to be associated with substantial costs that place extra demands on the household budgets and increase financial stress. Disability may also curtail ability to raise cash; such effects may occur through loss of income earning potential (i.e. wages foregone). The coefficients for disability are consistent with these expectations.

Living in a household with both Indigenous and non-Indigenous people residents could be an indicator of exposure to non-Indigenous social networks comprising those less likely to be disadvantaged and more likely to be cashed up. Interestingly, living with non-Indigenous people is not significantly associated with financial stress but is significantly associated with financial security. Accordingly, such households appear to affect Indigenous outcomes through an enhanced ability to raise cash quickly.

Customary activities of hunting and gathering for either food or medicines can influence financial stress or security, by augmenting household production and thereby substituting for what would otherwise be purchased. Another potential explanatory variable is a dummy variable that captures whether an individual lives on a remote 'homeland' - broadly defined in the Macquarie Atlas of Indigenous Australia gas 'an Indigenous person's ancestral country' (Arthur and Morphy 2005: 262). ${ }^{4}$ The reason why homeland is included in the analysis is because the productivity aspect of hunting and gathering activities is likely to be higher when a person has an intimate knowledge of the local country.

In general, either living on homelands or customary activities is significant when analysing financial security and financial stress models (but both explanations are not significant in any one model). For example, homelands are associated with lower financial stress but are not significantly associated with financial security. Hunting and gathering is significantly associated with financial security at the $10 \%$ level, but is not significant for financial stress. This may reflect that there is either some sort interaction between hunting and gathering and homelands or that these explanations are capturing the same underlying factor (say connection with indigenous culture).

The other largely Indigenous-specific factor, which is controlled for in both the GSS and NATSISS regression, is living in a multi-family household. This is associated with lower levels of financial stress, but is not associated with the ability to raise a substantial amount of cash within a week. Multi-family

4 The ABS (2007: 111) quite rightly point out that people may not live in their ancestral lands permanently; it is a geographic sense of belonging that relates to an individual rather than an area. 
households may act as a form of social insurance for Indigenous families, in terms of an informal line of credit to other household members. Interestingly, there is no significant association between multi-family households and lower levels financial stress for 'all Australian families' which probably indicates the distinct nature of Indigenous intra-household sharing which is more likely to involve kinship and other social obligations (Altman and Hunter 1998).

\section{Social exclusion, social inclusion and Indigenous poverty}

Policy makers focus on a number of issues that are often correlated with poverty - including economic disadvantage, social exclusion and social capital - although such issues are clearly not synonymous with poverty. The above analysis illustrates that there is good reason to suspect Indigenous poverty is of a different order to other poverty and may be qualitatively different in nature. The concept of social exclusion may further motivate an understanding of why Indigenous poverty may be fundamentally different to other Australian poverty. This concept arose partially as a response to the perceived inadequacy of the poverty literature which focused excessively on income at a point in time (Spicker 2007). Social exclusion and the related concept of social inclusion emphasise the importance of social relationships with the broader society and are concerned with social processes that are intrinsically dynamic in nature. For a racial minority such as Indigenous Australians, discrimination is a clear example of a problem with social relationships that may lead to social exclusion.

Previous research has highlighted the existence of social exclusion by demonstrating the lack of correlation between income and selected economic, political, health, crime and other social outcomes (Hunter 1999, 2000). While these findings are easily replicated using more recent data, this section focuses on the unique discrimination data provided in the 2008 NATSISS. If discrimination is found to exist for high income groups, this is direct evidence that social exclusion is likely to be evident even when resources are not scarce.

The following analysis measured discrimination for Indigenous households ranked by the overall Australian distribution of equivalised household income. Given the small number of Indigenous households in the fourth and fifth quintiles of Australian incomes, those observations are grouped together so that estimates are reasonably reliable. Note that this top income category represents the top 40 per cent of household incomes in Australia - and such households can in no way be construed as poor. 
In the not too distant past, practices that could be considered discriminatory were condoned or even encouraged by the state (Arrow 1998). The rise of antidiscrimination legislation in the 1970s means that any ongoing discriminatory behaviour is more likely to be indirect or covert than overt discrimination (Walker 2001). Covert discrimination is relatively self-explanatory, but indirect discrimination can occur when criteria or practices appear on the surface to be neutral but can lead to exclusions due to other characteristics such as race. Statistical discrimination based on the average characteristics of a group is a welldocumented form of racial discrimination which is sometimes justified in terms of the right of firms to maximise their profits. The widespread privilege given to managerial prerogative in the institutions that regulate industrial relations makes it difficult to identify both indirect and covert forms of discrimination - as evidenced by the small number of prosecutions of labour market discrimination under the Racial Discrimination Act 1975 (De Plevitz 2000; Hunter 2005).

Fig. 10.4 Discrimination by equivalised income quintile, Indigenous Australia, 2008

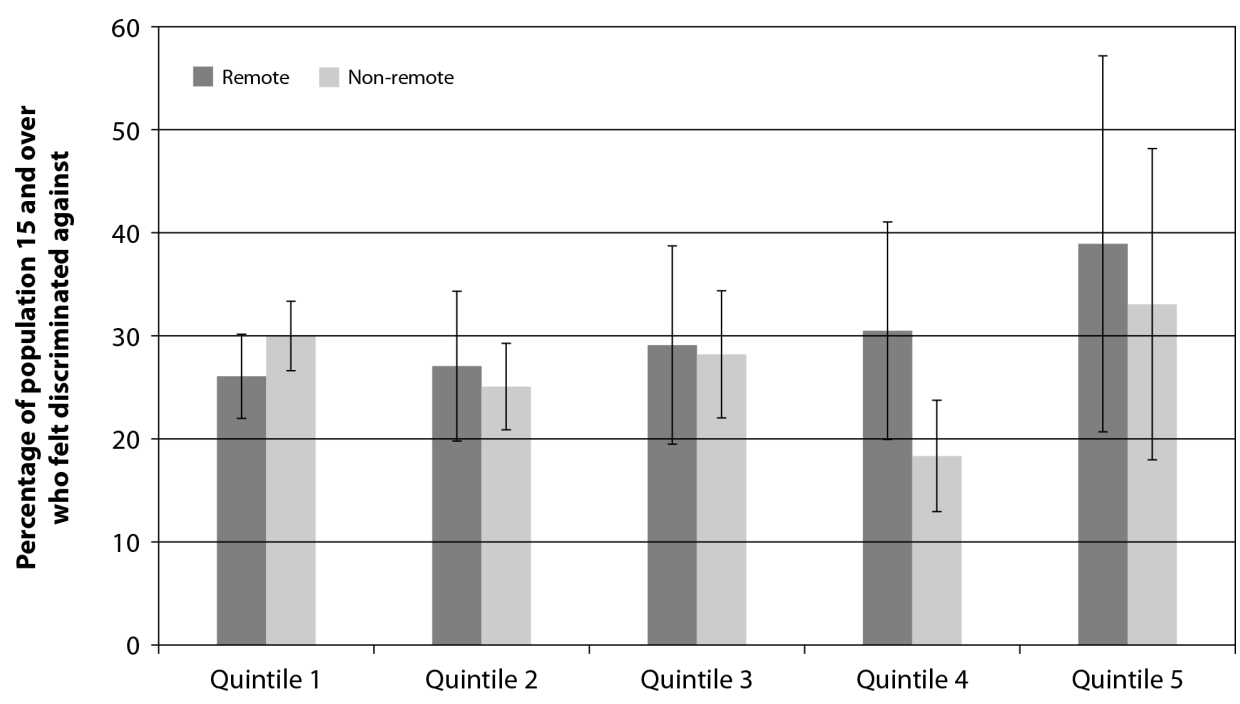

Equivalised household income quintile (Australia)

Note: Data on experience of discrimination was not collected in GSS.

Source: Author's customised calculations using the 2008 NATSISS (accessed using the RADL)

While the official level of discrimination reported is often low, the actual experience of discrimination by Indigenous people appears to be quite high. Indeed, Fig. 10.4 shows that around 30 per cent of Indigenous residents in both remote and non-remote areas report experiencing some form of discrimination. Perhaps the most important observation in Fig. 10.4 is that there is no income gradient for the experience of discrimination. Discrimination affects both the 
rich and poor alike and is one of the fundamental reasons why Indigenous people feel socially excluded from national life. Obviously, it is hard to prove that discrimination exists legally, but the subjective experience or feeling of being discriminated against is potentially important in its own right, in driving the willingness to participate in broader societal processes.

\section{Research questions and answers}

By combining information from two datasets - the 2006 GSS, and the 2008 NATSISS - it is possible to answer, more or less completely, the questions raised at the beginning of this chapter.

\section{Research question 1: Is there a role of customary Indigenous practices and non-market activities in explaining poverty and financial stress?}

The answer is clearly 'yes', although the precise role of customary practices and activities needs considerable work. Living on homeland, and hunting and gathering activities, do seem to interact but further work is needed to clarify the nature of the interaction. One improvement to the specification is likely to be that the models are separately run for remote and non-remote population. This was not done here to simplify exposition but a disaggregated model is likely to be warranted (see Biddle 2011).

\section{Research question 2: Is income measurement error or differential household size and composition driving the difference between Indigenous and other Australian poverty?}

The analysis presented in this chapter indicates that Indigenous equivalence scales are likely to be significantly different from equivalence scales derived for other populations. All poverty studies use culturally specific assumptions for the mainstream population and are likely to embed significant measurement error in existing estimates of Indigenous poverty. This observation includes those estimates of Indigenous poverty reported above, which use the internationally accepted OECD equivalence scales. While equivalence scales were not estimated in this chapter, the empirical analysis points strongly to the possibility that Indigenous equivalence scales are likely to differ from standard equivalence scales. 


\section{Research question 3: What is the relationship between poverty and social exclusion of Indigenous Australians?}

Many Indigenous people experience multiple disadvantage, which can be construed as social exclusion (Hunter 2009; Steering Committee for the Review of Government Service Provision 2009). This chapter has shown that social relationships are likely to be an important aspect of Indigenous social exclusion, especially the ongoing experience of discrimination. In order to understand Indigenous disadvantage, it is not sufficient to examine income, or even financial stress, as discriminatory processes affect even well-endowed Indigenous households.

\section{Research question 4: Is Indigenous poverty different from other poverty?}

The answer to the above three questions means that the answer to this question which provides the underlying motivation for the chapter - is a resounding 'YES'.

\section{Data gaps and future research directions}

Several data issues arose in the analysis. First, the mixing of individual and household-level information in explaining what is arguably a household-level phenomenon: poverty and financial stress. Historically, poverty was seen as a family-level analysis but many analyst have pointed out that it is less culturally biased to focus on the household level (Altman and Hunter 1998; Hunter 2001, 2006; Hunter, Kennedy and Biddle 2004). The main argument is that many cultures do not have social relations that are directly comparable to nuclear families as they have evolved in modern western economies. Rather than ignore these alternative social forms, it is preferable to use households rather than focus on specific types of family. Note that the controls for multi-family households are only one aspect of the different cultural forms in the social lifealbeit a quite important aspect in the context of Indigenous Australia - and it is preferable to analyse the household as it is the largest unit available.

The practical difficulty of analysing household-level phenomenon using information that is only collected for individuals is an intractable difficulty. Collecting data from all people in the household, rather than a random or 
representative individual, would appear to be preferable as this can add considerably to the cost of data collection, exacerbate problems of incomplete data, and considerably complicate analysis.

The adequacy of the nature of the geographic information on GSS and NATSISS, particularly the Indigenous survey, is an issue for this analysis. The statutory requirement for the $\mathrm{ABS}$ to ensure confidentiality of respondents combines with a desire to ensure that separate estimates can be constructed for each State and Territory to mean that there is no consistent disaggregated information on local accessibility of an area beyond the remote versus non-remote variable. I argue that it would be preferable to include disaggregated information on accessibility of an area rather than be constrained to reporting uneven categories of accessibility for each State because of historical accidents and different stages of development. For example, less developed jurisdictions like the Northern Territory do not have major metropolitan areas with good accessibility to services. The problem is most pronounced in States and Territories where there is not a sufficient number of respondents to distinguish between, for example, metropolitan, inner regional and outer regional. Given that accessibility to services is likely to be a key factor underlying Indigenous and other development, it would be analytically preferable to ignore the State and Territory information and report the most disaggregated level information available on accessibility. A separate data file for State and Territory level information could be provided on request to administrators and researchers focused on specific jurisdictions; however, it is more important that accessibility to services be consistently available for most research purposes.

This chapter highlights that there is probably some value in pursuing social exclusion based explanations of poverty. Such explanations focus on the social relationships and processes underlying disadvantage, especially Indigenous poverty. Income at a particular point in time only captures one aspect of Indigenous disadvantage, and low levels of social capital and discrimination may reinforce Indigenous disadvantage. If one adopts a social exclusion lens to interpret poverty, with its emphasis on processes, this drives the conclusion that cross-sectional data such as that collected in GSS and NATSISS is not adequate. We need to collect longitudinal information that charts people's pathways into and out of poverty with a view to identifying the factors that reinforce Indigenous disadvantage. The Household, Income and Labour Dynamics in Australia (HILDA) Survey is a large sample household-based panel study which permits some of this sort of analysis for the general Australian population. ${ }^{5}$ There is no analogous survey for the Indigenous population, although the Longitudinal Study of Indigenous Children (LSIC) does collect information on approximately

5 HILDA began in 2001 and collects information annually about economic and subjective wellbeing, labour market dynamics and family dynamics. 
1500 children and their families; the study is focused on 11 geographic sites, each with a potentially unique historical context. Some information on the dynamics of household disadvantage may be pervaded by LSIC, but it only collected household information pertaining to child development and will not be an adequate basis for understanding the overall dynamics of Indigenous disadvantage. Indigenous poverty and social exclusion are areas worthy of study in their own right. Failure to properly describe such issues is likely to misrepresent and understate Indigenous disadvantage. More importantly, it will prevent the formulation of effective policy informed by a real understanding of these pressing issues.

\section{Appendix 10A: Tables}

Table 10A.1 Descriptive statistics for GSS regressions

\begin{tabular}{|c|c|c|}
\hline Description & Mean & Std. Dev. \\
\hline Any cash problems in the last 12 months & 0.1924 & 0.3942 \\
\hline Could raise $\$ 2000$ cash within a week & 0.8345 & 0.3717 \\
\hline Log of equivalised household income (OECD) & 6.5016 & 0.7646 \\
\hline Number of people in household & 2.4875 & 1.3471 \\
\hline Multi-family household & 0.0179 & 0.1325 \\
\hline Owner without a mortgage & 0.3300 & 0.4702 \\
\hline Owner with a mortgage & 0.3478 & 0.4763 \\
\hline Index of Relative Socio-Economic Disadvantage & 5.6717 & 2.8335 \\
\hline Couple family & 0.5320 & 0.4990 \\
\hline One parent family & 0.0814 & 0.2735 \\
\hline Profound or severe disability & 0.0564 & 0.2307 \\
\hline Unspecified disability & 0.1430 & 0.3501 \\
\hline Other regional & 0.2115 & 0.4084 \\
\hline Inner Regional & 0.2225 & 0.4159 \\
\hline Major city & 0.5661 & 0.4956 \\
\hline New South Wales & 0.1484 & 0.3556 \\
\hline Victoria & 0.1387 & 0.3456 \\
\hline Queensland & 0.1360 & 0.3428 \\
\hline South Australia & 0.1142 & 0.3181 \\
\hline Western Australia & 0.1190 & 0.3238 \\
\hline Tasmania & 0.1327 & 0.3393 \\
\hline Northern Territory & 0.0964 & 0.2951 \\
\hline Australian Capital Territory & 0.1145 & 0.3184 \\
\hline Number of observations & 11465 & \\
\hline
\end{tabular}


Survey Analysis for Indigenous Policy in Australia

Table 10A.2 Descriptive statistics for NATSISS regressions

\begin{tabular}{|c|c|c|}
\hline Description & Mean & Std. Dev. \\
\hline Any cash problems in the last 12 months & 0.2337 & 0.4232 \\
\hline Could raise $\$ 2000$ cash within a week & 0.4698 & 0.4991 \\
\hline Log of equivalised household income (OECD) & 6.0741 & 0.6775 \\
\hline Number of people in household & 3.5039 & 2.0708 \\
\hline Multi-family household & 0.0902 & 0.2865 \\
\hline Owner without a mortgage & 0.0851 & 0.2791 \\
\hline Owner with a mortgage & 0.1936 & 0.3952 \\
\hline Index of Relative Socio-Economic Disadvantage & 2.9509 & 2.3801 \\
\hline Couple family & 0.5244 & 0.4995 \\
\hline One parent family & 0.2884 & 0.4530 \\
\hline Profound or severe disability & 0.0849 & 0.2788 \\
\hline Unspecified disability & 0.4267 & 0.4946 \\
\hline NSW Inner Regional & 0.0446 & 0.2063 \\
\hline NSW Outer Regional & 0.0281 & 0.1652 \\
\hline Vic Total & 0.1723 & 0.3776 \\
\hline Qld Major Cities & 0.0219 & 0.1464 \\
\hline Qld Inner Regional & 0.0201 & 0.1404 \\
\hline Qld Outer Regional & 0.0239 & 0.1528 \\
\hline Qld Remote/Very Remote & 0.0951 & 0.2934 \\
\hline WA Non-Remote & 0.0561 & 0.2302 \\
\hline WA Remote/Very Remote & 0.0739 & 0.2616 \\
\hline NT Remote/Very Remote & 0.1121 & 0.3155 \\
\hline Balance of Australia - Non-remote & 0.2498 & 0.4329 \\
\hline Balance of Australia - Remote/Very Remote & 0.0473 & 0.2122 \\
\hline Indigenous and non-Indigenous members in household & 0.4186 & 0.4934 \\
\hline Lives on homeland & 0.2371 & 0.4253 \\
\hline Hunting and gathering for medicines & 0.0446 & 0.2063 \\
\hline Hunting and gathering for food & 0.3758 & 0.4844 \\
\hline Number of observations & 5413 & \\
\hline
\end{tabular}

Source: Author's customised calculations using the 2008 NATSISS (accessed using the RADL) 


\section{References}

Akerlof, G. A. and Kranton, R. E. 2010. Identity Economics, Princeton University Press, Princeton.

Altman, J. C. and Hunter, B. H. 1997. 'Indigenous poverty since the Henderson Report', CAEPR Discussion Paper No. 127, CAEPR, ANU, Canberra.

and 1998. 'Indigenous poverty', in R. Fincher and J. Nieuwenhuysen (eds), Australian Poverty: Then and Now, Melbourne University Press, Melbourne.

Arrow, K. J. 1998. 'What has economics to say about racial discrimination', Journal of Economic Perspectives, 12 (2): 91-100.

Arthur, W. S. and Morphy, F. (eds) 2005. Macquarie Atlas of Indigenous Australia, Macquarie Library Pty Ltd, Sydney.

Australian Bureau of Statistics (ABS) 2007. Housing and Infrastructure in Aboriginal and Torres Strait Islander Communities: Australia 2006, cat. no. 4710.0, ABS, Canberra.

Biddle, N. 2011. 'Income, work and Indigenous livelihoods', Lecture 5, Measures of Indigenous Wellbeing and Their Determinants Across the Lifecourse, 2011 CAEPR Online Lecture Series, CAEPR, ANU, Canberra.

Bourdieu, P. 1993. Sociology in Question, Sage, London.

Breunig, R. and Cobb-Clark, D. 2006. 'Understanding the factors associated with financial stress in Australian households', Australian Social Policy, 2005: 13 -64 .

Coleman, J. S. 1988. 'Social capital in the creation of human capital', American Journal of Sociology, 94 (S): 95-120.

Daly, A. and Smith, D. 1995. 'The economic status of Indigenous Australian families', CAEPR Discussion Paper No. 93, CAEPR, ANU, Canberra.

De Plevitz, R. L. 2000. The Failure of Australian Legislation on Indirect Discrimination to Detect the Systemic Racism which Prevents Aboriginal People From Fully Participating in the Workforce, PhD thesis, Centre for Public and Comparative Law Faculty of Law, Queensland University of Technology, Brisbane.

Hunter, B. H. 1999. 'Three nations, not one: Indigenous and other Australian poverty', CAEPR Working Paper No. 1, CAEPR, ANU, Canberra. 
2000. 'Social exclusion, social capital and Indigenous Australians: measuring the social costs of unemployment', CAEPR Discussion Paper No. 204, CAEPR, ANU, Canberra.

2001. 'Tackling poverty among Indigenous Australians', in R. Fincher and P. Saunders (eds), Creating Unequal Futures, Allen and Unwin, Sydney.

2005. 'The role of discrimination and the exclusion of Indigenous people from the labour market', in D. Austin-Broos and G. Macdonald (eds), Culture, Economy and Governance in Aboriginal Australia, University of Sydney Press, Sydney.

- 2006. 'Further skirmishes in the Poverty War: Income status and financial stress among Indigenous Australians', Australian Journal of Labour Economics, 9 (1): 51-64.

2009. 'Indigenous social exclusion: Insights and challenges for the concept of social inclusion', Family Matters, 82: 52-61.

- Kennedy, S. and Biddle, N. 2004. 'Indigenous and other Australian poverty: Revisiting the importance of equivalence scales', Economic Record, 80 (251): 411-22.

— the reliability of income distributions: Some evidence for Indigenous and other Australians', Economic Record, 79 (244): 70-83.

Jordan, K. and Hunter, B. H. 2009. 'Indigenous social exclusion and inclusion: what are people to be included in, and who decides?', Impact, Spring: 18-21.

Robeyns, I. 2000. ‘An unworkable idea or a promising alternative? Sen's capability approach re-examined', Discussion Paper 00.30, Center for Economic Studies, Katholieke Universiteit, Leuven.

Ross, R. T. and Mikalauskas, A. 1996. 'Income poverty among Indigenous families with children: Estimates from the 1991 Census', CAEPR Discussion Paper No. 110, CAEPR, ANU, Canberra.

Rowley, C. D. 1970. The Remote Aborigines, ANU Press, Canberra.

— 1972. Outcasts in White Australia, Penguin, Melbourne.

Saunders, P. 2005. The Poverty Wars: Reconnecting Research with Reality, UNSW Press, Sydney. 
_- Naidoo, Y. and Griffiths, G. 2007. 'Towards new indicators of disadvantage: Deprivation and social exclusion in Australia', SPRC Report 12/07, University of New South Wales, Sydney.

Sen, A. 1982. Poverty and Famines: An Essay on Entitlements and Deprivation, Clarendon Press, Oxford.

-1993. 'Capability and well-being', in M. Nussbaum and A. Sen (eds), The Quality of Life, Clarendon Press, Oxford.

2000. Development As Freedom, Alfred A Knopf, New York.

1992. Inequality Re-examined, Oxford University Press, Oxford.

Smith, D. E. 1991. 'Towards an Aboriginal household expenditure survey: Conceptual, methodological and cultural considerations', CAEPR Discussion Paper No. 10, CAEPR, ANU, Canberra.

Spicker, P. 2007. The Idea of Poverty, The Policy Press, Bristol.

Steering Committee for the Review of Government Service Provision 2009. Overcoming Indigenous Disadvantage: Key Indicators 2009, Productivity Commission, Melbourne.

Walker, I. 2001. 'The changing nature of racism: From old to new?', in M. Augoustinos and K.J. Reynolds (eds), Understanding Prejudice, Racism, and Social Conflict, Sage, London.

Whiteford, P. 1985. 'A family's needs: Equivalence scales, poverty and social security', Research Paper No. 27, Department of Social Security, Development Division, Canberra.

Woolcock, M. and Narayan, D. 2000. 'Social capital: Implications for development theory, research, and policy', The World Bank Research Observer, 15 (2): 225-49. 